\title{
The Distribution of Non-clause Bound Reflexives in Northeast Ohio English ${ }^{1}$
}

Sara Schmelzer Loss $\bullet$ Cleveland State University $\bullet$ s.loss $<$ at $>$ csuohio.edu

1. Introduction Non-clause bound (NCB) reflexives in English challenge Chomsky's (1981) Binding Theory, which states that a reflexive and its antecedent must be (roughly) in the same clause (Pollard \& Sag 1993, Reinhart \& Reuland 1993, Zribi-Hertz 1989, Baker 1995, Fasold 2003, inter alia). Below is an example of a NCB reflexive in American English. Coreference is indicated with subscripts, and clauses are indicated with brackets (Ross 1970: 227).

(1) Tom $_{i}$ believed [that the paper had been written by Ann and himself $\mathrm{i}_{\mathrm{i}}$. Despite extensive research, the distribution of non-clause bound (NCB) reflexives (e.g., himself) in American English remains largely unknown (Baker 1995: 74). Additionally, the distribution of reflexives in American English may be changing (Fasold 2003). Cross-linguistic research suggests that the distribution of NCB reflexives differ across languages and dialects (Cole et al 2001). This paper examines the distribution of NCB reflexives in Northeast Ohio English (NOE), which are licensed by Point of View, as a step toward understanding the current distribution of American English reflexives.

2. Overview of NCB reflexives NCB reflexives typically share a number of characteristics across languages: (i) they lack some or all markings for person, number, or gender (Pica 1987); (ii) they occur in non-finite, subjunctive, or nominal clauses (Pica 1987); (iii) they occur in nonargument positions in English (Reinhart \& Reuland 1993); and (iv) they are licensed by pragmatic environment (e.g., Sells 1987, Zribi-Hertz 1989). Sells (1987: 455) claims that pragmatically licensed NCB reflexives are a result of the interaction of the following three primitive notions: (i) SOURCE: The one who makes the report; (ii) SELF: The one whose "mind" is being reported; and (iii) PIVOT: The one from whose physical point of view the report is made.

Effects of these primitive roles on NCB reflexives have been found in various languages. For example in some languages, coreference with a higher nominal expression is "blocked" when there is an intervening subject that does not match a lower subject for person (Mandarin, Cole \& Sung 1994: 363). ${ }^{2}$ Huang and Liu (2001) claim that Blocking is due to a conflict between the internal and external SOURCE in a sentence. Below is an example of blocking in Mandarin.

(2) * Zhangsan ${ }_{\mathrm{i}}$ renwei $\left[n i_{\mathrm{j}} \quad\right.$ zhidao [Wangwu $\mathrm{K}_{\mathrm{k}}$ xihuan ziji $\left.\left.\mathrm{i}_{\mathrm{i}}\right]\right]$

Zhangsan think you know Wangwu like self

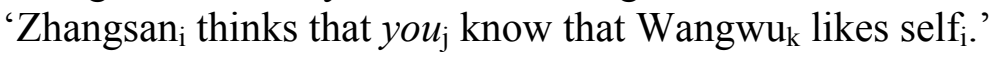

Furthermore, a NCB reading is prevented in some languages when the embedded clause contains when but not because (Japanese, Sells 1987:455). Sells claims this difference is due to SELF effects since because, but not when, denotes that the external speaker is making a judgment about the causal relation between two events from the internal protagonist's point of view.

(3) Takasi $_{i}$ wa [Yosiko ga mizu o zibun ${ }_{i}$ no ue ni kobosita\{node/*toki\}] nurete-simatta

Takasi $_{i}$ TOP [Yosiko SUBJ water OBJ self $f_{i}$ GEN on LOC spilled \{because/*when\}] wet-got

"Takasi $i_{i}$ got wet $\{$ because/*when $\}$ Yosiko spilled water on self $f_{\mathrm{i} .}$ "

Lastly, verbs like come, but not go, allow for NCB readings of reflexives (Mandarin, Liu 1999). Liu (1999) claims that this distribution is due to PIVOT effects: a "deictic center," which indicates physical point of view, can license NCB reflexives.

\footnotetext{
${ }^{1}$ Thanks to Stephanie Chenevert, who helped with data collection and organization. Thanks also to the Northeast Ohio and Minneapolis/St. Paul area English speakers who participated in the study. All errors are mine.

${ }^{2}$ Mandarin Blocking Effects are asymmetrical: $1^{\text {st }}$ and $2^{\text {nd }}$ person pronouns can block a $3^{\text {rd }}$ person noun from being $\mathrm{NCB}$, but a $3^{\text {rd }}$ person noun cannot prevent a $1^{\text {st }}$ or $2^{\text {nd }}$ person pronoun from being NCB (Huang \& Liu 2001).
} 
(4) Mama shuo [jia chuqu-de nuer yijing hui \{lai/*qu\} ziji-de jia le]. Mother say marry go-out daughter already return come/go self's home SFP "Mother ${ }_{i}$ said that [the married daughter $]_{j}$ already came/*went back to self' $\mathrm{s}_{\mathrm{i}}$ home." 3. Methods 18 speakers of NOE, who were all affiliated with Cleveland State University, participated in the study (ages $18-41, M=25.4, S D=7.2$ ). Northeast Ohio is part of the Inland North dialect area (Labov et al 2006). To my knowledge, no literature suggests that NOE syntax is non-standard. Previously collected judgments of similar sentences from 12 English speakers from Minneapolis, MN and St. Paul, MN (MSP) were used as a control (Loss 2011; ages 23-56, $M=36.5, S D=9.66$ ). Stimuli included both non-clause bound oneself and himself/herself as well as clause bound reflexives in a variety of environments. The stimuli were delivered in a random order using the E-Prime 2.0 software (Psychology Software Tools, Pittsburgh, PA). Each stimulus began with a short situation that supported a specific (NCB or clause bound) reading. Next, there was a target sentence that indicated intended coreference with capital letters. Finally, there was an open field for the naturalness rating. Naturalness judgments were collected using Magnitude Estimation (Bard et al 1996). Magnitude Estimation allows informants to "build" their own naturalness rating scale, which is advantageous because it does not restrict participants to a set scale. Results were normalized following Engen (1971); statistics analysis used Program R (2012).

4. Results NOE speakers were more likely than MSP English speakers to rate sentences with NCB reflexives as natural $(\mathrm{p}=.027 ; M=8.39, M=1.3)$ :

(5) $\mathrm{Sam}_{\mathrm{i}}$ hopes [that his parents forgive himself $\mathrm{i}_{\mathrm{i}}$.

NOE speakers rated sentences with NCB himself and oneself similarly, though NCB oneself was rated as more natural than $\mathrm{NCB}$ himself $(\mathrm{p}=0.09 ; \mathrm{M}=5.77, \mathrm{M}=10.04)$ :

(6) $\left\{\mathrm{He}_{i} / \mathrm{One}_{i}\right\}$ hopes [that others will vote for $\left\{\right.$ himself $_{i} /$ oneself $\left._{i}\right\}$ ].

This trend is not surprising since, cross-linguistically, NCB reflexives lack some or all person, number, and gender features (Pica 1987). Due to this trend, most of the analyses were done using sentences with NCB oneself rather than himselflherself.

Interestingly, NOE speakers overwhelmingly preferred use of the reflexive pronoun over the personal pronoun in adjunct position ( $\mathrm{p}=0.03 ; \mathrm{M}=10.02, \mathrm{M}=3.78)$.

(7) One $_{\mathrm{i}}$ hopes [a banker will loan money to $\left\{\right.$ oneself $\left._{i} / *_{\text {one }}\right\}$ ].

In NOE, an intervening first person or second person subject or object prevents a NCB reading ( $\mathrm{p}=0.05 ; \mathrm{M}=5.59, \mathrm{M}=3.79, \mathrm{M}=10$, respectively):

(8) a. One $\mathrm{i}_{\mathrm{i}}$ hopes [that $\left\{* ? /{ }^{*}\right.$ you/a banker $\}$ will loan oneself $\mathrm{f}_{\mathrm{i}}$ money].

b. One $\mathrm{i}_{\mathrm{i}}$ might hear from $\{*$ ?me/*you/someone $\}$ [that people will vote for oneself $\mathrm{f}_{\mathrm{i}}$ ].

Similarly, an intervening third person subject prevents a NCB reading of myself $(\mathrm{p}=0.05)$ :

c. ${ }^{*} \mathrm{I}_{\mathrm{i}}$ think [my goldfish loves myself $\mathrm{f}_{\mathrm{i}}$ ( $(\mathrm{M}=4.37$; Fasold 2003)

In contrast, an intervening nominal expression in subject position that does not match the reflexive for number did not prevent a NCB reading $(\mathrm{p}=0.2 ; \mathrm{M}=6.32)$ :

d. One $_{i}$ hopes [that they will loan money to oneself $\mathrm{f}_{\mathrm{i}}$ ].

Because, but not when, allows a NCB interpretation ( $\mathrm{p}=.05 ; \mathrm{M}=5.13, \mathrm{M}=8.4)$ :

e. One $\mathrm{i}_{\mathrm{i}}$ cries $\left[\{\right.$ ? when/because $\}$ a jerk hits oneself $\left.\mathrm{f}_{\mathrm{i}}\right]$.

Finally, NCB reflexives can come after both come and go. $(\mathrm{p}=0.9174 ; \mathrm{M}=7.48, \mathrm{M}=6.1)$ :

f. One $\mathrm{i}_{\mathrm{i}}$ may want [family to $\{$ come $/$ go $\}$ visit oneself $\mathrm{f}_{\mathrm{i}}$.

Thus, NOE exhibits NCB reflexives. NCB oneself is slightly preferred over himself. NCB reflexives can originate in finite clauses in both argument and non-argument positions. Finally, NCB reflexives can corefer with nominal expressions in subject or object position. A non-clause 
bound interpretation is not allowed in the following two environments: (i) when there is an intervening subject or object that does not agree with the reflexive for person and (ii) when the embedded clause begins with when rather than because or that.

5. Analysis Recent research by Guéron and Haegeman (2012) claims that Point of View is licensed by syntax in West Flemish since there is an overt POV morpheme. Therefore, the following is a syntactic analysis for the distribution of NCB reflexives in NOE that capitalizes on the role of point of view. I propose an Agree operation and covert raising to a POV-op Head to account for NCB interpretations (c.f. Chou 2012). I assume a phase based analysis using Chomsky's (2001: 14) version of the Phase Impenetrability Condition.

Following Chou (2012), Huang and Liu (2001), and Tenny (2006)'s analyses of NCB reflexives in Mandarin and Japanese, I assume a functional head in the left periphery of phases (i.e., $\mathrm{CP}$ and $\nu \mathrm{P}$ ) allows for full interpretation of the attitude bearer. I follow Chou's (2012: 12) formalization of the functional head as a Point-of-View-op (POV-op), which includes values for [discourse participant] ([d]) and [addresser] ([a]), illustrated below:

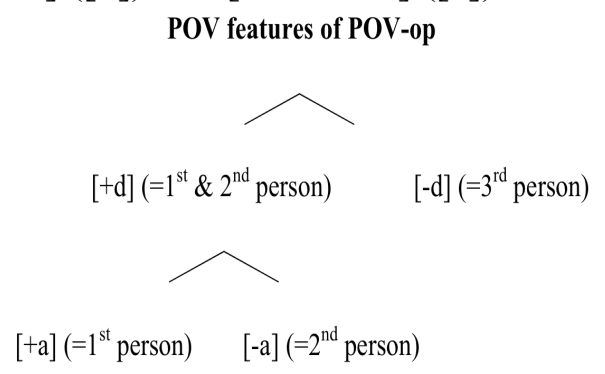

Logophoric expressions, which are often considered to be doubly anaphoric, have unvalued [ud] and $[u$ a] features. These features are valued via a probe-goal relation between a noun and the POV-op. Logophoric expressions raise in LF to the POV-op to create an input for self-ascription of (de se) attitude (Huang \& Liu 2001, Chierchia 1989). Crucially, all POV (d, a) features must match at their final, raised position to ensure correct ascription of attitudes (Chuo 2012:15).

Below are examples of full derivations: the first derivation does not have Blocking Effects, and the second derivation has Blocking Effects. Some successive-cyclic movements are not illustrated for readability.

g. One $\mathrm{i}_{\mathrm{i}}$ hopes [that a banker will loan oneself $\mathrm{f}_{\mathrm{i}}$ money].

a. $\quad\left[v \mathrm{P}\right.$ oneself $\left.[u \mathrm{~d}, u \mathrm{a}, u \mathrm{VAR}]-\mathrm{POV}-\mathrm{op}_{[u \mathrm{~d}, u \mathrm{a}]} \ldots t\right]$

b. a banker $\ldots\left[v \mathrm{p}\right.$ oneself $\left.\mathrm{f}_{[-\mathrm{d},-\mathrm{a}, u \mathrm{VAR}]}-\mathrm{POV}-\mathrm{op}_{[-\mathrm{d},-\mathrm{a}]} \ldots t\right]$

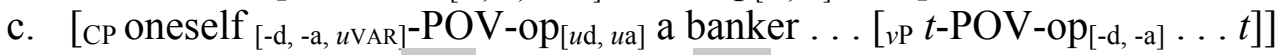

d. One $_{\mathrm{i}} \ldots\left[{ }_{\mathrm{CP}}\right.$ oneself $\mathrm{i}_{[-\mathrm{d},-\mathrm{a}, \mathrm{vaR}]}-\mathrm{POV}-\mathrm{op}_{[-\mathrm{d}, \mathrm{-a}]}$ a banker $\ldots\left[{ }_{\nu \mathrm{P}} t-\mathrm{POV}-\mathrm{op}_{[-\mathrm{d},-\mathrm{a}]} \ldots t\right]$ An example of a subject triggering Blocking Effects is below:

h. *?One ${ }_{i}$ hopes [that you will loan oneself $f_{i}$ money].

a. $\quad\left[v \mathrm{P}\right.$ oneself $\left.[u \mathrm{~d}, u \mathrm{a}, u \mathrm{VAR}]-\mathrm{POV}-\mathrm{op}_{[u \mathrm{~d}, u \mathrm{a}]} \ldots t\right]$

b. you $\ldots\left[{ }_{\nu \mathrm{P}}\right.$ oneself $\left.[+\mathrm{d},-\mathrm{a}, u \mathrm{VAR}]-\mathrm{POV}-\mathrm{op} \mathrm{P}_{[+\mathrm{d},-\mathrm{a}]} \ldots t\right]$

c. $\left[\mathrm{CP}\right.$ oneself $[+\mathrm{d},-\mathrm{a}, u \mathrm{VAR}]-\mathrm{POV}-\mathrm{op}_{[u \mathrm{~d}, u \mathrm{a}]}$ you $\left.\ldots\left[v \mathrm{p} t-\mathrm{POV}-\mathrm{op}_{[+\mathrm{d},-\mathrm{a}]} \ldots t\right]\right]$

d. One $_{\mathrm{i}} \ldots\left[\right.$ [CP Oneself $\left._{\mathrm{i}}[+\mathrm{d}, \mathrm{-a}, \mathrm{VAR}]-\mathrm{POV}-\mathrm{op}[-\mathrm{d}, \mathrm{a}] \mathrm{you} \ldots\left[{ }_{v \mathrm{P}} t-\mathrm{POV}-\mathrm{op}_{[+\mathrm{d},-\mathrm{a}]} \ldots t\right]\right]$

If we assume that objects also c-command reflexives and that processes must occur as soon as possible, this analysis also accounts for objects triggering blocking. Moreover, positing a POVop in the left periphery can account for the blocking effects of when, as illustrated above in (11). Recall that when prompts an interpretation that represents the speaker's POV. In contrast, because prompts an interpretation that represents the (matrix) subject's POV (Iida and Sells 1986). Thus, because requires that the logophor raise to a position where it is locally c- 
commanded by the (matrix) subject, but when requires that the logophor raises to the highest POV-op. The highest POV is always valued as $[+d,+a]$ to match the speaker of the utterance, so the POV values cannot match (Chou 2012).

6. Conclusion \& Implications Currently, there are two types of reflexives in NOE: locally bound reflexives and NCB reflexives that are licensed by point of view. The distribution of reflexives as described by Reinhart \& Reuland (1993) is not consistent with NOE NCB reflexives. Though NCB reflexives in American English seem exceptional, their behavior can be accounted for by using the infrastructure that is already in place to account for NCB reflexives in other languages, such as Mandarin and Japanese. This study suggests that a POV-operator is on the right course for a cross-linguistic pragmatics and syntax interface. This research leads to questions about how reflexives behave in other regional and social dialects of English.

\section{References}

Baker, C. L. (1995). Contrast, Discourse Prominence, and Intensification, with Special Reference to Locally Free Reflexives in British English. Language, 71(1), 63-101.

Bard, E. G., Robertson, D., \& Sorace, A. (1996). Magnitude Estimation of Linguistic Acceptability. Language, 72(1), 32-68.

Chierchia, G. (1989). Anaphora and attitudes de se. In Semantics and contextual expression, ed. R. Bartsch, J. van Benthem \& P. van Emde Boas, 1-31. Dordrecht: Foris.

Chou, C-T T. (2012). Syntax-Pragmatics Interface: Mandarin Chinese Wh-the-hell and Point-of-View Operator. Syntax, 15(1): 1-24.

Cole, P., G. Hermon, \& C. L. Lee (2001). Grammatical and discourse conditions on long distance reflexives in two Chinese dialects. In P. Cole, G. Hermon and C.-T. Huang eds. Long Distance Reflexives. Academic Press: 1-46.

Cole, P., \& Wang, C. (1996). Antecedents and blockers of long distance reflexives: the case of Chinese Ziji. Linguistic Inquiry, 27(3).

Engen, T. (1971). Psychophysics II: Scaling methods. In Woodworth and Schlossberg's experimental psychology (pp. 47-86). New: Holt, Rinehart, and Winston.

Fasold, R. W. (2003). Language change in variation and formal syntax. American Speech, Supplement 88, $223-247$.

Guéron, J. \& L. Haegeman. 2012. Je est un autre. Subject positions, point of view and the neuter pronoun tet in West Flemish. Functional heads. Eds, L.Brugé, A. Cardinaletti, G. Giusti, N. Munaro, C. Poletto. Oxford: Oxford University Press. 81-91.

Hicks, G. (2009). The derivation of anaphoric relations. Amsterdam: John Benjamins Publishing Company.

Huang, C.-T. J., \& Liu, C.-S. L. (2001). Logophoricity, attitudes and ziji at the interface. Syntax and Semantics, (33), 141-196.

Labov, W., S. Ash, \& C. Boberg. (2006). The Atlas of North American English: Phonology, Phonetics, and Sound Change. A Multimedia Reference Tool. Berlin: Mouton de Gruyter.

Loss, S. (2011). Iron Range English Long-distance Reflexives. Dissertation. University of Minnesota - Twin Cities.

Oshima, D. (2012). GO and COME revisited: What serves as a reference point? In Proceedings of Berkeley Linguistics Society (BLS), vol.32: 287-298.

Pica, P. (1987). On the Nature of the Reflexivization Cycle. NELS 17, GLSA, University of Massachusetts: Amherst, 2: 483-499.

Pollard, C. \& I. Sag. (1992). Anaphors in English and the Scope of the Binding Theory. Linguistic Inquiry (23): 261-303.

Reinhart, T. \& Reuland, E. (1993). Reflexivity. Linguistic Inquiry, 24, 657-720.

Ross, J. R. (1970). On declarative sentences. In R. A. Jacobs \& P. S. Rosenbaum (Eds.), Readings in English transformational grammar. Georgetown University Press: 222-272.

Sells, P. (1987). Aspects of Logophoricity. Linguistic Inquiry, 18(3): 445-479.

Tenny, C. (2006). Evidentiality, experiencers, and the syntax of sentience in Japanese. Journal of East Asian Linguistics, 15: 245-288.

Zribi-Hertz, A. (1989). Anaphor binding and narrative point of view: English reflexive pronouns in sentence and discourse. Language, 65(4), 695-727. 